\title{
EFEITO DA ADIÇÃO DE FITASE EM RAÇÕES DE FRANGOS DE CORTE, DURANTE AS FASES DE CRESCIMENTO E FINAL ${ }^{1}$
}

\author{
Effect of phytase addition in broiler rations, during grower and final phases
}

\author{
Patrícia Araújo Brandão ${ }^{2}$, Fernando Guilherme Perazzo Costa ${ }^{3}$, \\ Jocelyn Santiago Brandão ${ }^{4}$,José Humberto Vilar da Silva ${ }^{5}$
}

\begin{abstract}
RESUMO
Os experimentos tiveram como objetivo avaliar os efeitos da enzima fitase nas rações de frangos de corte sobre o desempenho e avaliação de carcaça durante os períodos de crescimento ( 21 a 35 dias) e final ( 36 a 45 dias de idade). Duas rações comerciais foram utilizadas, sendo a primeira formulada por uma empresa integradora de frangos de corte (E-1) e a segunda sugerida pela empresa fornecedora da enzima (E-2). Os tratamentos foram: T1 e T4 - ração sem adição da enzima e T2 e T3 - ração com fitase. O delineamento experimental utilizado foi o inteiramente casualizado, em arranjo fatorial 2 × 2 (duas rações e dois níveis de enzima), com nove repetições e trinta aves por parcela. A enzima fitase foi adicionada na quantidade de $100 \mathrm{~g} / \mathrm{t}$. Houve diferença significativa $(\mathrm{P}<0,01)$ para ganho de peso e conversão alimentar na fase de crescimento, não ocorrendo o mesmo na fase final $(\mathrm{P}>0,05)$. Quanto à avaliação dos rendimentos de partes das aves, só o de pernas apresentou diferença significativa com a ração formulada pela E-2, sem fitase. As rações formuladas pela E-1 apresentaram melhores resultados de desempenho, quando comparadas com as rações sugeridas pela E-2.
\end{abstract}

Termos para indexação: Avaliação de carcaça, avicultura, desempenho, enzimas.

\begin{abstract}
The objective of experiments were evaluate to effect of phytase in broilers rations, during growing (22 to 35 days) and final (36 to 45 days of age) phases. Two experimental rations were used each phase, whereas the first diet recommended by the the broiler integration (C-1) and the second suggested by furnished company enzyme (C-2). Treatments consisted in T1 and T4 rations without enzyme and T2 and T3 - rations with enzyme. A complete randomized design was used in a $2 \times 2$ factorial model (two rations $\mathrm{x}$ two levels of enzyme) with nine replicates and thirty birds per unit. The enzyme was used in $100 \mathrm{~g} / \mathrm{ton}$ of ration. Statistically significant difference $(\mathrm{P}<0.01)$ was found among the treatments to weight gain and feed:gain ratio to growing phase, not happened identical with final phase $(\mathrm{P}>0.05)$. The birds yield parts evaluation was statistically different $(\mathrm{P}<0.01)$ in legs yield with experimental rations suggested by E-2, without phytase. The rations formulated with the E-1 that showed better results in relation to rations $\mathrm{E}-2$
\end{abstract}

Index terms: Carcass valuation, poultry, performance, enzymes.

\section{(Recebido em 11 de agosto de 2005 e aprovado em 23 de julho de 2006)}

\section{INTRODUÇÃO}

Com o aumento na produção de frangos de corte, os nutricionistas têm se empenhado em buscar soluções para atender as exigências nutricionais das aves que, devido ao rápido crescimento e a conseqüente redução no tempo de abate, passaram a exigir alimentos de melhor qualidade, como também a utilizarem aditivos que façam com que os frangos aproveitem melhor o valor nutricional desses alimentos.

A avicultura é uma atividade econômica que desempenha papel de grande importância na estrutura agropecuária do Brasil, sendo um constante desafio para os técnicos obterem maior produtividade com menores custos.
Vários pesquisadores (CLASSEN et al., 1985; LYONS, 1996) têm estudado o efeito benéfico do uso de enzimas exógenas na alimentação de frangos de corte, visando uma melhora no desempenho dos animais. Uma importante fonte de fósforo são os ingredientes de origem vegetal, porém a maior parte encontra-se combinado com o inositol formando a molécula do ácido fítico ou hexafosfato de inositol que formam uma ampla variedade de sais insolúveis, diminuindo assim a solubilidade e a digestibilidade dos nutrientes.

Dentre os minerais exigidos pelas aves, o fósforo e o cálcio são considerados os mais importantes, por serem necessários não apenas para ótima taxa de crescimento, mas também para a mineralização óssea. $\mathrm{O}$ fósforo participa nos processos metabólicos e na absorção de nutrientes,

${ }^{1}$ Parte da dissertação do primeiro autor do PPGZ/CCA/UFPB.

${ }^{2}$ Aluna do Programa de Pós-Graduação em Zootecnia da UFPB - Campus II - 58397-000 - Areia, PB - Bolsista CNPq - patriciaaraujobrandao@bol.com.br

${ }^{3}$ Professor do DZ/CCA/UFPB - Campus II - Areia, PB - 58397-000, fperazzo@cca.ufpb.br

${ }^{4}$ Professor substituto do DCFS/CCA/UFPB - Campus II - 58397-000 - Areia, PB.

${ }^{5}$ Professor do DAP/CFT/UFPB - Campus III - 58220-000 - Bananeiras, PB - jvilar@cft.ufpb.br 
além de ser o mineral que mais onera o custo das rações. Entretanto, a alimentação de frangos de corte baseia-se em alimentos de origem vegetal, nos quais aproximadamente $66 \%$ do $\mathrm{P}$ (fósforo) está na forma de fitato (hexa-fosfato de inositol), segundo Rostagno et al. (2000).

A molécula de fitato é um grande fator antinutricional para monogástricos, possuindo em sua estrutura grupos ortofosfatos altamente ionizáveis, os quais afetam a disponibilidade de cátions como o cálcio, zinco, cobre, magnésio e ferro no trato gastrointestinal, o que resulta na formação de complexos insolúveis (SOHAIL \& ROLAND, 1999). Os grupos ortofosfatos podem também unir-se às enzimas digestivas e proteínas dietéticas, reduzindo a digestibilidade de carboidratos e aminoácidos (SEBASTIAN et al., 1996). Segundo Ravindran et al. (1995), como a habilidade da ave em utilizar o fósforo fítico é baixa, a biodisponibilidade do elemento fósforo nos ingredientes de origem vegetal também é muito baixa, necessitando da adição do fósforo inorgânico e propiciando maior custo da alimentação.

A enzima fitase é produzida por muitas espécies de bactérias, fungos e leveduras e é capaz de eliminar as propriedades antinutricionais do fitato. Esta enzima é produzida em escala comercial por um número limitado de organismos, sendo o cepas de Aspergillus os mais importantes. Muitos experimentos já foram conduzidos durante os últimos dez anos para demonstrar os efeitos da fitase microbiana na utilização de fósforo pelos frangos (COUSINS, 1999). Em perus, o efeito positivo da adição da fitase na digestibilidade do nitrogênio foi observado por Yi et al. (1996).

A enzima fitase catalisa o desdobramento do ácido fosfórico do inositol, liberando deste modo o ortofosfato para ser absorvido (NEWMAN, 1997). O uso desta enzima nas rações, com a finalidade de aumentar o aproveitamento do fósforo orgânico, que está na forma de fitato nos ingredientes de origem vegetal, vem sendo pesquisado com o intuito de reduzir o custo da adição do fósforo inorgânico na ração.

Com o presente trabalho, buscou-se avaliar os efeitos da fitase nas rações para frangos de corte, durante as fases de crescimento e final de criação.

\section{MATERIALE MÉTODOS}

O trabalho foi conduzido no Módulo de Avicultura do Departamento de Zootecnia do Centro de Ciências Agrárias da UFPB, Areia - PB. O experimento foi dividido em dois períodos: crescimento (22o ao $35^{\circ}$ dia) e final (36ao $46^{\circ}$ dia de idade) das aves.
Foram utilizados 1080 frangos de corte machos com 21 dias de idade, com peso médio de $863 \mathrm{~g}$ e $1.880 \mathrm{~g}$ para as fases de crescimento e final, respectivamente. As aves foram da marca comercial Ross, distribuídas em delineamento inteiramente casualizado (GOMES, 1990), no esquema fatorial 2 × 2 (duas rações experimentais x dois níveis de enzima) com nove repetições, totalizando 36 parcelas com 30 aves por unidade experimental.

A fitase utilizada foi a Natuphos® 5000, produzida pela empresa BASF, sendo caracterizada por um pó de cor amarelo pardo, obtido através de fermentação promovida por fungos do grupo Aspergillus niger e foi usada na dosagem de $100 \mathrm{~g} / \mathrm{t}$ de ração, como recomendado pelo fabricante.

As aves foram criadas até os 21 dias de idade com uma ração com $23 \%$ de proteína bruta e $2.930 \mathrm{kcal} / \mathrm{kg}$ de energia metabolizável (EM) para a fase pré-inicial e $21 \%$ de proteína bruta e $3.050 \mathrm{kcal} / \mathrm{kg}$ EM para a fase de inicial. Para as fases seguintes, crescimento e final, em cada experimento utilizaram-se aves diferentes. Ao final de cada fase analisada, pesaram-se as aves e sobras de ração, para em seguida avaliar o desempenho (consumo de ração, ganho de peso e conversão alimentar) e rendimento de carcaça, partes nobres (perna e peito) e gordura abdominal dos animais.

Foram utilizadas duas rações experimentais, sendo a primeira formulada por um empresa integradora de frangos de corte no Estado da Paraíba (E-1) e a segunda, formulada pela empresa fornecedora da enzima (E-2), cada uma delas com e sem adição da fitase e de acordo com as recomendações de Rostagno et al. (2000).

As rações foram formuladas à base de milho e farelo de soja, mantendo-se isoenergéticas e isoprotéicas, com $19 \%$ de PB e $3.180 \mathrm{kcal} / \mathrm{kg}$ de EM na fase de crescimento e $18 \%$ de $\mathrm{PB}$ e $3.250 \mathrm{kcal} / \mathrm{kg}$ de EM na fase final, como mostra a Tabela 1.

As aves foram alojadas em 36 boxes de alvenaria, medindo cada um 1,40 x 1,90 m de dimensões, com piso de cimento coberto com cama de bagaço de cana. Utilizou-se um comedouro tubular e um bebedouro pendular em cada um destes boxes.

Ao término do experimento, aos 45 dias, após um período de jejum de 8 horas, foram abatidas quatro aves por parcela, de acordo com o peso médio de cada repetição, para que fossem determinados os rendimentos de carcaça (RC), pernas (RPN) e peito (RPT), com pele e ossos, e gordura abdominal (GA). O rendimento de carcaça foi feito em relação ao peso vivo das aves ao abate, enquanto que o RPN, RPT e GA em relação à carcaça eviscerada. 
TABELA 1 - Composição percentual e química calculada das rações experimentais, no período de crescimento e final.

\begin{tabular}{|c|c|c|c|c|}
\hline \multirow{3}{*}{ Ingredientes } & \multicolumn{4}{|c|}{ Rações com enzima (\%) } \\
\hline & \multicolumn{2}{|c|}{ Crescimento } & \multicolumn{2}{|c|}{ Final } \\
\hline & $(\mathrm{E}-1)$ & (E-2) & $(\mathbf{E}-1)$ & (E-2) \\
\hline Milho & 64,31 & 65,76 & 66,21 & 67,71 \\
\hline Soja Extrusada & 21,30 & 16,10 & 25,10 & 19,80 \\
\hline Farelo de Soja (45\%) & 8,50 & 13,50 & 3,40 & 8,50 \\
\hline Farinha de carne e ossos & 4,65 & 2,95 & 4,25 & 2,55 \\
\hline Calcário calcítico & 0,40 & 0,85 & 0,35 & 0,75 \\
\hline Sal & 0,35 & 0,36 & 0,30 & 0,32 \\
\hline DL - Metionina (99\%) & 0,25 & 0,25 & 0,15 & 0,15 \\
\hline L-Lisina $(78,4 \%)$ & 0,03 & 0,02 & 0,03 & 0,01 \\
\hline Suplemento Vitamínico ${ }^{1}$ & 0,02 & 0,02 & 0,02 & 0,02 \\
\hline Suplemento Mineral $^{2}$ & 0,05 & 0,05 & 0,05 & 0,05 \\
\hline CL Colina & 0,04 & 0,04 & 0,04 & 0,04 \\
\hline Coban 400 (Monesina sódica) ${ }^{3}$ & 0,06 & 0,06 & 0,06 & 0,06 \\
\hline Enradin (Enramicina) ${ }^{3}$ & 0,08 & 0,08 & 0,08 & 0,08 \\
\hline Colistin (Bacitracina de zinco) ${ }^{3}$ & 0,08 & 0,08 & 0,08 & 0,08 \\
\hline Banox $^{4}$ & 0,01 & 0,01 & 0,01 & 0,01 \\
\hline Natuphos $^{5}$ & 0,01 & 0,01 & 0,01 & 0,01 \\
\hline Tot a 1 & 100,00 & 100,00 & 100,00 & 100,00 \\
\hline \multicolumn{5}{|l|}{ Valores calculados ${ }^{1}$} \\
\hline Proteína Bruta ( \% ) & 19,00 & 19,00 & 18,00 & 18,00 \\
\hline Energia Metabolizável (kcal/kg) & 3.180 & 3.180 & 3.250 & 3.250 \\
\hline Lisina total $(\%)$ & 1,05 & 1,05 & 0,88 & 0,88 \\
\hline Metionina + Cistina $(\%)$ & 0,85 & 0,85 & 0,75 & 0,75 \\
\hline Fósforo Disponível (\%) & 0,43 & 0,43 & 0,40 & 0,40 \\
\hline Cálcio (\%) & 0,95 & 0,95 & 0,90 & 0,90 \\
\hline
\end{tabular}

${ }^{1}$ Suplemento Vitamínico

${ }^{2}$ Suplemento Mineral

${ }^{3}$ Promotores de crescimento

${ }^{4}$ Antioxidante

${ }^{5}$ Nome comercial da enzima fitase (BASF)

Níveis de Suplementação de Vitaminas, Minerais e Aditivos (quantidade por kg/ração): Vit. A, 10.000UI; Vit.D 2.000UI; Vit. E, 30 UI; Vit. B, 2 mg; Vit. B 3 mg; Ac. Pantotênico, 12 mg; Biotina, 0,1 g; Vit. K 3 mg; Ácido fólico, 1 mg; Ácido nicotínico, $50 \mathrm{mg}$; Coxistac 12 (Salinomicina 12\%), $66 \mathrm{mg} ; 15 \mathrm{mg}$, cloreto de Colina (60\%), $6 \mathrm{mg}$; BHT, $1 \mathrm{mg}$; Vit. B ${ }_{12}$,, $015 \mathrm{mg}$, Selênio, 0,25 mg, Manganês, $106 \mathrm{mg}$; Ferro, $100 \mathrm{mg}$; Cobre, $20 \mathrm{mg}$; Cobalto, $2 \mathrm{mg}$; Iodo, $2 \mathrm{mg}$ e Excipiente q.s.p. $1.000 \mathrm{~g}$.

As análises estatísticas das variáveis estudadas foram realizadas utilizando-se o programa SAEG 8.0, desenvolvido pela Universidade Federal de
Viçosa (UFV, 1999). Na comparação das médias dos tratamentos, usou-se o teste $\mathrm{F}$, ao nível de $5 \%$ de probabilidade. 


\section{RESULTADOS E DISCUSSÃO}

\section{Período de crescimento (22 a 35 dias de idade)}

Os valores médios de ganho de peso (GP), consumo de ração (CR) e conversão alimentar (CA) deste período de criação estão apresentados na Tabela 2 .

Pelos resultados obtidos, observou-se que houve diferença significativa $(\mathrm{P}<0,01)$ entre os tratamentos para ganho de peso e conversão alimentar, sem haver, portanto, interferência da utilização da fitase sobre as duas rações sugeridas pelas empresas. Estes resultados coincidem com os obtidos por Bonato et al. (2001), McKnight (1999) e Sebastian et al. (1996).

Houve efeito significativo $(\mathrm{P}<0,01)$ para conversão alimentar, em que se verifica que a E-1 sem enzima apresentou melhor resultado em comparação aos demais tratamentos. Estes resultados estão coerentes com Ledoux et al. (1998) e Zhang et al. (1998).

Quanto ao consumo de ração, os tratamentos não diferiram estatisticamente $(\mathrm{P}>0,01)$ entre si, demonstrando dessa maneira, que a enzima fitase não influenciou neste parâmetro pesquisado. Resultados semelhantes foram encontrados por Bonato et al. (2001), Sebastian et al. (1996) e Tejedor et al. (2001), que também não verificaram efeito da adição da fitase nas rações para esta variável. Por outro lado, estes dados discordam dos resultados encontrados por Ledoux et al. (1998), Quian et al. (1996) e Zhang et al. (1998) que observaram aumento no CR quando utilizaram a fitase nas rações de frangos de corte.

\section{Fase final (36 a 45 dias de idade)}

Na Tabela 3 são mostrados os resultados de consumo de ração (CR), ganho de peso (GP) e conversão alimentar (CA) dos frangos de corte durante o período final de criação.

Os resultados obtidos mostram que não houve diferença significativa $(\mathrm{P}>0,05)$ entre tratamentos para nenhuma das variáveis estudadas. Esses resultados estão confirmando os dados encontrados por Bonato et al. (2001) e Sebastian et al. (1996) que não observaram efeito significativo com a inclusão da fitase nas rações de frangos de corte. Da mesma forma, assemelham-se com os resultados obtidos por Biehl \& Baker (1997) que, trabalhando com fêmeas, não verificaram diferenças entre tratamentos para GP e CA. Porém, trabalhando com machos, afirmaram que a CA melhorou com a utilização da enzima fitase. Para Conte et al. (2001) e Tejedor et al. (2001), os resultados obtidos no presente trabalho estão contrários aos observados nesta pesquisa porque os autores observaram aumento no $\mathrm{GP}$ e redução na CA.

Laurentiz et al. (2004), trabalhando com frangos de corte, adicionando fitase em dietas com diferentes níveis de zinco, verificaram que o nível de $1000 \mathrm{FTU} / \mathrm{kg}$ de ração resultou no melhor desempenho das aves de 1 a 21 dias e de 1 a 42 dias de idade, porém, na fase de 35 a 42 dias de idade foi observado que as aves do tratamento sem a inclusão de enzima, as quais vinham apresentando os piores desempenhos, tiveram um ganho de peso compensatório e conseqüentemente apresentaram melhor conversão alimentar.

Em relação ao $\mathrm{CR}$, estes resultados estão semelhantes aos encontrados por Bonato et al. (2001), Sebastian et al. (1996) e Tejedor et al. (2001) que não observaram efeito significativo nessa variável, através da inclusão da fitase nas rações de frangos de corte. Por outro lado, adicionando enzimas nas rações de frangos de corte, Conte et al. (2001) observaram um aumento do CR, enquanto que Pizzolante et al. (2000) observaram redução para essa mesma variável.

As médias de rendimento de carcaça (RC), de pernas (RPN) e de peito (RPT), com pele e ossos, e de gordura abdominal (GA), ao final do experimento, estão mostradas na Tabela 4.

O tratamento com enzima da E-2 apresentou um resultado superior no rendimento de perna em relação aos demais tratamentos, diferenciando-se principalmente do tratamento 1 (E-1) sem enzimas. Estes resultados mostraram-se semelhantes aos encontrados por Kornegay et al. (1998) quando adicionaram a enzima, mas contrários ao Huff et al. (1998) em relação ao RPN, RPT e GA. Esses resultados demonstraram que a enzima estudada não teve o efeito esperado, uma vez que são utilizadas nas rações com o objetivo de melhorar o rendimento das aves, já que promovem uma diminuição da viscosidade intestinal, melhorando também a digestão e absorção dos nutrientes no trato digestivo destes animais. 
TABELA 2 - Efeito dos níveis da fitase sobre o desempenho de frangos de corte Ross, machos, no período de crescimento.

\begin{tabular}{cccccc}
\hline Tratamentos & Origem & $\begin{array}{c}\text { Enzima } \\
(\mathbf{g} / \mathbf{t})\end{array}$ & $\begin{array}{c}\text { Consumo de } \\
\text { ração (kg/ave) }\end{array}$ & $\begin{array}{c}\text { Ganho de peso } \\
\text { (kg/ave) }\end{array}$ & $\begin{array}{c}\text { Conversão } \\
\text { alimentar (kg/kg) }\end{array}$ \\
\hline 1 & Empresa 1 & 0 & $2,049 \mathrm{a}$ & $1,098 \mathrm{a}$ & $1,867 \mathrm{c}$ \\
2 & Empresa 1 & 100 & $2,039 \mathrm{a}$ & $1,068 \mathrm{ab}$ & $1,909 \mathrm{bc}$ \\
3 & Empresa 2 & 100 & $2,018 \mathrm{a}$ & $1,028 \mathrm{~b}$ & $1,968 \mathrm{ab}$ \\
4 & Empresa 2 & 0 & $2,033 \mathrm{a}$ & $1,021 \mathrm{~b}$ & $1,993 \mathrm{a}$ \\
\hline Média & - & - & 2,035 & 1,054 & 1,934 \\
\hline CV & - & - & 2,21 & 3,57 & 2,94 \\
\hline
\end{tabular}

Médias seguidas de letras diferentes, dentro de cada coluna, diferem estatisticamente pelo Teste de Tukey $(\mathrm{P}<0,05)$

TABELA 3 - Efeito dos níveis da fitase sobre o desempenho de frangos de corte Ross, machos, no período final.

\begin{tabular}{cccccc}
\hline Tratamentos & Origem & $\begin{array}{c}\text { Enzima } \\
(\mathbf{g} / \mathbf{t})\end{array}$ & $\begin{array}{c}\text { Consumo de } \\
\text { ração (kg/ave) }\end{array}$ & $\begin{array}{c}\text { Ganho de peso } \\
\text { (kg/ave) }\end{array}$ & $\begin{array}{c}\text { Conversão } \\
\text { alimentar (kg/kg) }\end{array}$ \\
\hline 1 & Empresa 1 & 0 & $1,846 \mathrm{a}$ & $0,816 \mathrm{a}$ & $2,262 \mathrm{a}$ \\
2 & Empresa 1 & 100 & $1,852 \mathrm{a}$ & $0,803 \mathrm{a}$ & $2,306 \mathrm{a}$ \\
3 & Empresa 2 & 100 & $1,881 \mathrm{a}$ & $0,800 \mathrm{a}$ & $2,352 \mathrm{a}$ \\
4 & Empresa 2 & 0 & $1,894 \mathrm{a}$ & $0,812 \mathrm{a}$ & $2,334 \mathrm{a}$ \\
\hline Média & - & - & 1,868 & 0,808 & 2,319 \\
\hline CV & - & - & 4,39 & 7,00 & 4,29
\end{tabular}

Médias seguidas de letras diferentes, dentro de cada coluna, diferem estatisticamente pelo Teste de Tukey $(\mathrm{P}<0,05)$.

TABELA 4 - Efeito dos níveis da fitase sobre o rendimento de carcaça, pernas e peito e de gordura abdominal de frangos de corte Ross, machos, ao final do experimento.

\begin{tabular}{ccccccc}
\hline Tratamentos & Origem & $\begin{array}{c}\text { Enzima } \\
(\mathbf{g} / \mathbf{t})\end{array}$ & $\begin{array}{c}\text { RC } \\
(\mathbf{\%})\end{array}$ & $\begin{array}{c}\text { RPN } \\
(\boldsymbol{\%})\end{array}$ & $\begin{array}{c}\text { RPT } \\
(\mathbf{\%})\end{array}$ & $\begin{array}{c}\text { GA } \\
(\mathbf{\%})\end{array}$ \\
\hline 1 & Empresa 1 & 0 & $77,84 \mathrm{a}$ & $28,10 \mathrm{~b}$ & $28,59 \mathrm{a}$ & $2,11 \mathrm{a}$ \\
2 & Empresa 1 & 100 & $78,09 \mathrm{a}$ & $28,41 \mathrm{ab}$ & $28,37 \mathrm{a}$ & $2,23 \mathrm{a}$ \\
3 & Empresa 2 & 100 & $78,23 \mathrm{a}$ & $28,89 \mathrm{a}$ & $28,00 \mathrm{a}$ & $2,11 \mathrm{a}$ \\
4 & Empresa 2 & 0 & $78,74 \mathrm{a}$ & $28,51 \mathrm{ab}$ & $27,85 \mathrm{a}$ & $2,05 \mathrm{a}$ \\
\hline Média & - & - & 78,22 & 28,48 & 28,20 & 2,13 \\
\hline CV & - & - & 2,12 & 1,94 & 5,34 & 8,63 \\
\hline
\end{tabular}

Médias seguidas de letras diferentes, dentro de cada coluna, diferem estatisticamente pelo Teste de Tukey $(\mathrm{P}<0,05)$. 


\section{CONCLUSÃO}

A adição de fitase é importante ser utilizada na fase de crescimento, não sendo necessária na fase final de criação de frangos de corte.

\section{REFERÊNCIAS BIBLIOGRÁFICAS}

BIEHL, R. R.; BAKER, D. H. Microbial phytase improves amino acid utilization in young chicks fed diets based on soybean meal but not it diets based on peanut meal. Poultry Science, London, v. 76, p. 355-360, 1997.

BONATO, E. L.; ZANELLA, I.; ROSA, A. P. Efeito da adição de enzimas em dietas com níveis crescentes de farelo de arroz integral sobre o desempenho de frangos de corte. In: CONFERÊNCIA APINCO 2001 DE CIÊNCIA E TECNOLOGIA AVÍCOLAS, 2001, Campinas. Anais... Campinas: FACTA, 2001. p. 32.

CLASSEN, H. L.; CAMPBELL, G. L.; ROSSNAGEL, B. G. Studies on the hull barley in chick diets: deleterious effects and methods of avallution. Canadian Journal of Animal Science, Ottawa, v. 65, n. 3, p. 725-733, 1985.

CONTE, A. J.; TEIXEIRA, A. S.; SCHOULTEN, N. A. Efeito da fitase e xilanase em dietas com $15 \%$ de farelo de arroz, sobre o desempenho de frangos de corte aos 21 dias de idade. In: CONFERÊNCIAAPINCO 2001 DE CIÊNCIA E TECNOLOGIA AVÍCOLAS, 2001, Campinas. Anais... Campinas: FACTA, 2001. p. 26.

COUSINS, B. Enzimas na nutrição de aves. In: SIMPÓSIO INTERNACIONAL ACAV - EMBRAPA SOBRE NUTRIÇÃO DE AVES, 1999, Concórdia. Anais... Concórdia: [s.n.], 1999. p. 118-132.

GOMES, F. P. Curso de estatística experimental. 13. ed. Piracicaba: Nobel, 1990. 468 p.

HUFF, W. E.; MOORE, JUNIOR, P. A.; WALDROUP, P. W. Effect of dietary phytase and high available phosphorus corn on broiler performance. Poultry Science, London, v. 77, p. 1899-1904, 1998.

KORNEGAY, E. T.; ZHANG, Z.; DENBOW, D. M. Influence of microbial phytase supplementation of low protein/amino acid diet on performance ileal digestibility of protein and amino acids and carcass measurements of finishing broilers. Poultry Science, London, v. 77, n. 117, 1998. Supplement 1.
LAURENTIZ, A. C.; JUNQUEIRA, O. M.; FREITAS NETO, O. C.; VIEIRA, B. S. Avaliação da adição da enzima fitase em dietas com diferentes níveis de fósforo disponível para frangos de corte. In: CONFERÊNCIAAPINCO 2004 DE CIÊNCIA E TECNOLOGIA AVÍCOLAS, 2004, Santos. Anais... Santos: FACTA, 2004. p. 24.

LEDOUX, D. R.; BROOMHEAD, J. N.; FIRMAN, J. D. Efficacy of phytassed, a phytase containing transgenic canola, to improve phytate phosphorus utilization from cornsoybean meal diets fed turkey poults from day 1 to 35 . Poultry Science, London, v. 77, n. 54, 1999. Supplement 1.

LYONS, T. P. Goal 2000: a truly global science-based company that responds rapidly to emerging issues. In: NORTH AMERICA UNIVERSITY TOUR, 1996, Nicholasville. Anais... Nicholasville: Alltech, 1996. p. 1-32.

McKNIGHT, W. F. The impact of phytase and high available phosphorus corn on broiler performance and phosphorus excretion. In: PROCEEDINGS OF THE BASF TECHNICAL SYMPOSIUM, 1999, Atlanta, Georgia. Anais... Atlanta: BASF, 1999. p. 57-66. Seção 6.

NEWMAN, K. Phytase: the enzyme, its origin and characteristics: impact and potential for increasing phosphorus availability. In: SHORT COURSE ON FEED TECHNOLOGY, 7., 1997, Ansung. Anais... Ansung: KSANF, 1997. p. 169-177.

PIZZOLANTE, C. C.; TEIXEIRA, A. S.; SANTOS, C. D. Utilização da fitase na alimentação de frangos de corte: desempenho. In: CONFERÊNCIA APINCO 2000 DE CIÊNCIA E TECNOLOGIAAVÍCOLAS. FACTA, 2000, Campinas. Anais... Campinas: [s.n.], 2000. p. 45.

QUIAN, H.; KORNEGAY, E. L.; DENBOW, D. M. Phosphorous equivalence of microbial phytase in turkey diets as influenced by calcium to phosphorous ratios and phosphorus levels. Poultry Science, London, v. 76, p. 75-68, 1996.

RAVINDRAN, V.; BRYDEN, W. L.; KORNEGAY, E. T. Phytates: occurrence, bioavailability and implications in poultry nutrition. Poultry and Avian Biology Reviews, Northwood, v. 6, p. 125-143, 1995.

ROSTAGNO, H. S. et al. Tabelas brasileiras para aves e suínos: composição de alimentos e exigências nutricionais. Viçosa: UFV, 2000. 141 p. 
SEBASTIAN, S.; TOUCHBURN, S. P.; CHAVEZ, E. R. Efficacy of supplemental microbial phytase at different dietary calcium levels on growth performance and mineral utilization on broiler chickens. Poultry Science, London, v. 75, p. 1516-1522, 1996.

SOHAIL, S. S.; ROLAND, D. A. Influence al supplemental phytase on performance of broilers four to six of age. Poultry Science, London, v. 78, p. 550-555, 1999.

TEJEDOR, A. A.; ALBINO, L. F. T.; ROSTAGNO, H. S. Efeito da adição da enzima fitase sobre o desempenho e a digestibilidade ileal de nutrientes. Revista Brasileira de Zootecnia, Viçosa, v. 30, n. 3, p. 802-808, 2001.
UNIVERSIDADE FEDERAL DE VIÇOSA. SAEG - Sistema de Análises Estatísticas e Genéticas. Versão 8.0. Viçosa, 1999. $69 \mathrm{p}$.

YI, Z.; KORNEGAY, E. T.; DENBOW, D. M. Effect of microbial phytase on nitrogen and aminoacid digestibility and nitrogen retention of turkey poults fed corn-soybean diets. Poultry Science, London, v. 75, p. 979-990, 1996.

ZHANG, Z. B.; KORNEGAY, E. T.; DENBOW, D. M. Comparison of genetically engineered microbial and plant phytase for young broilers. Poultry Science, London, v. 77, n. 71, 1998. Supplement 1. 